\title{
Quality Requirements and Promotion of Professional Outdoor Sports Leader
}

\author{
Jian LIU \\ Wuhan Textile University, P.R. China, 430073
}

\begin{abstract}
Based on sample studies for students in Shenyang Institute of physical education, analysis shows the current outdoor sports in the universities in our country is still at an early stage of development. People interest a lot in outdoor sports, but due to professional sports team leaders are short. And people's expectations and will launch the campaign hopes in the leader. This requires a leader should possess high professional qualities, what's the quality requirements of leader, what about the upgrade policy? These articles discussed and put forward its own views.
\end{abstract}

KEYWORD: Universities; Outdoor sports; Professional leader; Quality; Promotion strategy

\section{INTRODUCTION}

Along with social progress, in development of sports knowledge is in a spiral, but also decide the education system should be an open, diverse and dynamic system. Outdoor sports is limited to existing school physical education classes were highly competitive running, jumping, throwing, climbing, beyond basic content development in the society and nature, so as to stimulate students ' motivation to learn, cultivate students ' interest in learning, develop the student's learning potential, developing their personalities, which is helpful for the students. Students also developed a fascination for the campaign.

However, due to the nature of the movement is an adventure, for security concerns, had to give up this interest. And a lot more are pinning their hopes on the professional leader, and collegiate professional outdoor leader is extremely scarce.

The lack of professional tour guides due to leaders of quality not up to professional standards, then what is the quality requirements of a leader? And how to improve the quality of leader?

\section{RESEARCH OBJECTS AND METHODS}

\subsection{Research objects}

Studies generally all students in Shenyang Institute of physical education. Is the Institute's sample of 200 students in this country from a freshman to senior year.

\subsection{Research methods}

\subsubsection{Literature research}

Through the collection and analysis of existing experts, scholars ' papers and monographs, including discussion on research contents related to outdoor sports and professional tour guides. In particular through the use of existing methods for statistical data analysis, research. Outdoor sports related studies are of two kinds:

The first category, outdoor activity mainly in curriculum in physical education in colleges and universities of the importance and feasibility of implementation. Analyses outdoor sports teaching system of curriculum structure and related key issues, but also emphasized the outdoors for an important role in the reform of physical education.

Second, the analysis focuses on the effect of outdoor exercise. Among them, including strengthening students ' physical quality and promoting development of psychological quality and enhance the ability of social adaptation, has a significant influence on the development of students' comprehensive qualities.

For related literature, author relevant theoretical concepts reference, but for the requirement for professional tour guides, as well as improve the policies carried out specific surveys and research.

\subsubsection{Research}

Using survey methods, through the use of a selfadministered questionnaire survey, including send method and set to answer method. Survey 
questionnaires were issued 200 to recover 178 valid 156 with the recovery of $89 \%$ and effective recovery of $87 \%$.

This study is a descriptive study. Units of analysis for individuals. By using the sampling method was used to investigate. Specific programmes for, first, random samples of a total of 200 in Shenyang Institute of physical education undergraduate course for librarians to select samples of four grades, respectively 50,50,50,50. The second, during junior year, senior student of outdoor sports in the sample selected 20 and the rest for non-sports students.

\section{RESULTS AND ANALYSIS}

\subsection{Related concepts}

\subsubsection{Specialty}

Classified by subject and social division of labor requires profound expertise in teaching and learning activities of the divisions units. This program defines properties that are both profound expertise in teaching and learning activities, but also has compartments of this unit of the property.

\subsubsection{Outdoor sports}

Mainly refers to "people in their leisure time, in order to meet their own health, to relax and rest, human communication, as well as the need for excitement and adventure, and many other, sport (walking, skiing, hiking, biking, etc) in the mountains, water and desert, plateau, carried out under the specific environment of a variety of outdoor activities."

Outdoor sports features: (1) activities in the sport way. (2) conducted in a specific environment. (3) the activity has a certain exploratory and challenging. (4) is a unique experience.

Divided according to the outdoor sports professional, outdoor sports can be divided into leisure outdoor sports and professional outdoor sports.

\subsubsection{Team Manager}

(1) Refers to lead a team or the person who led the team.

(2) Generally refers to the leading outbound missions Guide staff, which overseas leaders, by the group, accompanied by sending travelers abroad full accompanying persons. Lead demand is higher than the guide, team leaders often have experience in skilled guide the presidency, and must qualify as group leader qualified.

\subsection{Professional qualities of outdoor sports leaders in colleges}

\subsubsection{A wealth of theoretical knowledge}

Team leaders should fully understand the theoretical content of outdoor sports, master a variety of theories, including geography, outside medicine, dietetic hygiene, survival skills, knowledge of psychology. Understand the important role of team leader and aware of their responsibilities in order to give full play to the role of professional tour guides in actual operation.

\subsubsection{Enough practical capability}

\subsubsection{Professor of theoretical capacity}

University professional outdoor leader of professional teaching skills should be mastered, teaching students theoretical knowledge of outdoor sports-related, including teaching an introduction to outdoor sports, orienteering, outdoor survival skills, medicine, self-help, diet, health, risk factors, such as basic knowledge for help so that students acquire the relevant theoretical knowledge before the actual activity.

\subsubsection{Language skills}

It is the leader of the necessary quality to good at express their ideas clearly and persuasively. Leader's language should be simple, expression of refined, spirited, infectious, Contact at the actual student thinking, taking into account the student's level of understanding. Way taking should account the effectiveness of teaching, language should not be too long, nor too many pauses, lengthy explanations will make the student fatigue, and it is not consistent with the principles of intensive teaching practice more, practice improvement.

\subsubsection{Ability to develop basic skills}

Professional tour guides must teach students specialized in outdoor sports technology, outdoor survival skills and technology, outdoor first-aid skills, to enable students to the field of knowledge, technology, problem solving, to cultivate students' innovative spirit and practical ability, and response capabilities.

The lead should be through simulation exercises and scenarios for outdoor experience enables students to adapt to the environment have a good transition.

\subsubsection{Other qualities and ability}

Team leader need train to enhance the students' team spirit, enhance students' sense of cooperation; nourishing students' communication skills and interpersonal skills, strengthen their sense of identity and train students in management and organizational 
capacity, increase students' sense of responsibility. Meanwhile, as outdoor sports there are adventurous, team leaders should focus on students overcome the psychological fear and enhance students' ability to overcome difficulties.

\subsubsection{Comprehensive leadership qualities}

\subsubsection{Capacity planning}

Professional tour guides should have enough planning capabilities, to prepare and guide team members to engage in outdoor activities.

Activity program: Professional tour guides should be meticulously planned in advance, ready for active content.

Personnel: First of all, statistics on the activities of personnel, according to survey of students participating in activities for outdoor activity locations, time orientation will.

Secondly, understanding students' physical fitness, mental capacity, and so on.

Finally, mobilize each participant, identify team lead, in order to better understand their situation.

Route: The first step, according to the survey, with the actual situation, set the field locations.

The second step, before setting out detailed plans and familiarize them with the course, which should include the midway down the course and transport arrangements.

Third, teachers for field trips. Along the way to its topography, taking into account the possible security risks, and ways to address these risk factors.

The fourth step, try to get locals familiar with the landform and climate Wizard.

Funding: Leaders should set a good financial implications. Investment is not a lot of outdoor sports training, colleges and universities can fully devote the necessary start-up capital. Funding and equipment selected should be determined according to the outdoor sport training program content. Project is generally preferred for outdoor venues, there are extended to qualified field and water sports. So according to outdoor training program to purchase the required outdoor equipment, outdoor sports training without affecting the school teaching cases, outdoor sport training facility open to the community, so as to serve the society, but also "to keep things" recycling funds to fund later expansion. It also can expand to social sponsorship money. Apply to the national capital, or solicitation purposes are also address the funding approach.

Material preparation: Team leaders to remind students to prepared good basic equipment, tent, backpack, sleeping bag, clothing, shoes, cap, cookware, map, guide needle, head lamp (containing alternate bulb and battery), alternate food, alternate clothing, sun glasses, knife, fire, Notepad, pen and phone can said is most shortcut of help tool, but should note its service covered range, in some mountain between especially valley within, often because no signal and lost contact, Also note that saving mobile electricity. Meanwhile, prepared the required equipment. Finally, first-aid kit is the most indispensable.

\subsubsection{Organizational capability}

Organization of activities before and after: Before the event, team leader should communicate with students and understand the intentions of students, through collective activity so that we increase the sense of identity and a sense of trust. When active, advocates help each other and make everyone aware of their importance in the collective, collective consciousness and enhance the sense of responsibility, improve the cohesion of the member. After the event, and gain feedback from members views on the events in a timely manner, in order to promote activities to continue to improve and achieve better development.

Construction of protection: Since the outdoor sports venue is in a specific environment, outdoor activities is a process of profound contact with nature, Through the activities of environmental awareness and the establishment of codes of conduct, To make college students more deeply understand to take care of the nature, The need to protect nature, importance, and urgency, Learn to live in harmony with nature. This requires a team leader organizing students, pay attention to the protection of the building.

\subsubsection{Risk response capabilities:}

Many items in the outdoor sports is very challenging and very stimulating, risk and safety conscious there's not a moment to relax. Nature brings to you a happy and healthy at the same time, and filled with a variety of risks and uncertainties, so you must pay attention to safety, and security is a prerequisite for outdoor sports.

Leaders must ensure that the safety equipment is complete; choose the best locations and training content; outdoor sports is different from adventure and exploration. Without a security project is absolutely not to do; each project should make it clear before training methods as well as security considerations, to carry out the necessary security checks; sessions will also be strict supervision and management.

Accident risk preparedness in advance, if unforeseen circumstances in the activity, first of all, team leaders to calm the mood, calm feelings of injured students, nursing. Second, take all kinds of measures to reduce the risk of escalation, so other officers emotional stability. Third, completes the work, smooth finish. Afterwards, comfort measures taken against students who might have been injured, reducing psychological harm. 
Role of leader in this role link is the most important, because it is only in the most dangerous moments, he reflected as the leader in the panic of the moment, leaders must lead by example.

\section{DISCUSSION AND SUGGESTIONS}

This study student of Shenyang Institute of physical education for outdoor sports and its leader informed study summarizes the qualities of professional outdoor leader, discussed strategies to improve the quality of leader.

It is an earlier tour to explore this investigation of professional tour guides. Since the study was conducted by a University in Shenyang city, so it only shows part of the Shenyang region due to sample the sampling limitations, data research also need to be further explored. While theoretical concepts there are always different perspectives and do not have the same provisions, there will be different views.

In the hope that in future studies, specializing in outdoor sports can get more attention. Professional sports leader of the quality requirements to be able to get more attention and research, at the same time, the corresponding improvement strategy in order to better promote the development of the sport in colleges and universities.

\section{SUMMARY}

The study included investigation of the Shenyang Institute of physical education, discusses the theoretical concepts. Come to the professional qualities of outdoor sports leaders in colleges and universities, and improvement of relevant policies.

Qualities include: A wealth of theoretical knowledge, practical skills (professor of theoretical skills, language skills, ability to develop basic skills and other qualities and ability) and overall leadership skills (planning, organizational ability, risk response capacity).

Strategy: learning orientation knowledge, led for practicing and mastering and applying integrated skills.

\section{REFERENCES}

[1] Li Hong-yan. Study on the theory and practice of outdoor sports. Beijing University of physical education. $\mathrm{PhD}$ thesis, 2008 years 6 months

[2] Mr. CHAN, Dong Fan. Study of outdoor sports teaching system. Journal of Wuhan Institute of physical education, 40 volume 6, 2006 years 6 months

[3] Yang Han, Dong Fan. - Outdoor sports teaching system of physical education course in colleges and universities study. Beijing sport University, 28 volume 6, 2005 years 6 months

[4] Jianwei Zhang. Analysis of necessity and feasibility of outdoor sports in colleges and universities. Adult education, 2009 years 4 months, with a total 267. 